\title{
COLD EXPOSURE DURING ALPINE HELICOPTER RESCUE OPERATIONS
}

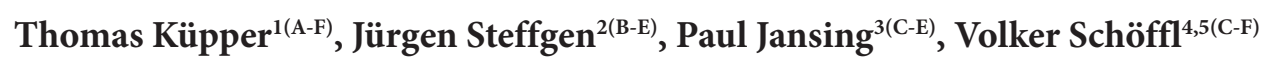 \\ ${ }^{1}$ Institute for Aerospace Medicine, Faculty of Medicine, Technical University of Aachen, Aachen, Germany \\ ${ }^{2}$ Department of Nephrology and Rheumatology, University of Göttingen, Göttingen, Germany \\ ${ }^{3}$ State Institute for Occupational Safety and Health of North Rhine Westfalia, Düsseldorf, Germany \\ ${ }^{4}$ Department of Trauma and Orthopedic Surgery, Klinikum Bamberg, Bamberg, Germany \\ ${ }^{5}$ Department of Trauma Surgery, Friedrich Alexander University Erlangen-Nuremberg, Nuremberg, Germany
}

\begin{abstract}
Objective: To evaluate the cold exposure of the personnel involved in helicopter rescue operations in an alpine environment to quantify the risk for frostbite or hypothermia.

Methods: The weather conditions, the locality and its altitude and the sojourn on scene of the rescue operations of 15 months in the region Oberwallis, Switzerland were analyzed. The equivalent chill temperature was estimated with two independent models. "Mean exposure” and „worst case situation“ were calculated. The results are evaluated according to the "classic" Siple-Passel-Model, the more recent model of Danielsson, ISO 11079, ISO 9920, the German industrial standard DIN 33403.5, and the German government regulations for work in cold environment ("G21").

Results: There were only marginal differences in chill temperature between both temperature models. Assuming "worst case conditions" the Siple-Passel-model showed $87.1 \%$ of the operations at chill temperatures $>-30^{\circ} \mathrm{C}, 12.1 \%$ in the range of -30 to $-45^{\circ} \mathrm{C}$, and $0,8 \%<-45^{\circ} \mathrm{C}$. The lowest temperature was $-54.6^{\circ} \mathrm{C}$. The Danielson model resulted in $77.6 \%$ without the risk of frostbite, $20.1 \%$ with $>5 \%$ risk, $6 \%>50 \%$ risk, and $1.8 \%>95 \%$ risk. According to DIN $1.5 \%$ of the operations were performed at chill temperatures higher than cold class 1. $2.3 \%$ are class $1,13.3 \%$ class $2,34.7 \%$ class $3,34.6 \%$ class 4 , and $13.7 \%$ class 5 . The maximal exposure times of DIN 33404.5 are exceeded in at least $0.5 \%$ of the missions. According to ISO 11079 clothing with 2.0 clo is sufficient in $40.2 \%$ rsp. $23.9 \%$ of the operations (summer, IREQ min. and IREQ neutr.). In winter the corresponding results are $0.3 \%$ and $0.0 \%$. Duration of limited exposure is exceeded in $9.1 \%$ (IREQ min.) rsp. $19.8 \%$ (IREQ neutr.) of the operations in summer and in $10.3 \% \mathrm{rsp} .19 .8 \%$ in winter. According to ISO 9920 ICL min. as well as ICL neutr. is exceeded in $100 \%$ in summer and winter operations.

Conclusions: Alpine rescue operations are a typical place of work in cold - sometimes extreme cold - environment. Because of the limited time of exposure during the majority of the operations the most important danger for rescue personnel is frostbite although hypothermia cannot be excluded in cases of prolonged operations. Special advice to avoid the specific risks must be given to the crews and an examination by occupational medicine, e.g. according to "working in cold environment, G21" of the German Berufsgenossenschaften, is recommended. Recommendations for adequate clothing are given.
\end{abstract}

Key words: occupational safety, alpine rescue, winch operations, cold injuries, hypothermia, prevention

\section{Introduction}

In comparison to urban emergencies those in alpine regions happen in an environment which causes some different exposures to the personnel, above all cold and altitude (hypobaric hypoxia). During several operations the personnel is exposed to extreme environmental conditions. However, there is a lack of data which could be used for recommendations in occupational medicine, particularly because of technical problems with data acquisition during alpine helicopter rescue operations. Beside other factors such operations are characterized by extreme pressure of time, limited number of personnel involved, limited hold in the helicopter, and limited load it can carry at high altitude. The limited time of measurement would give purely accidental results in an environment with changing conditions. Therefore it is impossible to obtain valid data on environmental conditions during the missions.

The goal of the study was to appraise the risk of personnel exposed to cold environment during alpine rescue operations with its quickly changing conditions. Because it is not realistic to get useful data during such operations we used an artificial (statistical) approach to estimate the cold exposure by combining the data of the accident's locality with the time of exposure and the coincident meteorological data assuming mean conditions and „worst case conditions“.

\section{Material and methods}

A retrospective analysis of 1082 rescue operations (456 days) was performed to obtain data about the exact time when the mission was carried out, the altitude of the location and the duration of exposure on 
scene. Two different methods were used to estimate the equivalent chill temperature on scene. The first one used data obtained by the ascent of meteorological balloons at Payerne (Kanton Waadt, distance to the location of the rescue operations $75-100 \mathrm{~km}$ ). The temperature corresponding to the altitude of the accident's location was converted into the equivalent chill temperature as described below using the wind speed and the temperature of the same altitude measured by the balloon.

The second method used the coincident air temperature of the next meteorological measuring point (Ulrichen, Kanton Wallis) as follows: Missions between 7 p.m. and 8 a.m. day's minimum temperature, those between 12 a.m. and 3 p.m. day's maximum temperature and the others the day's mean temperature. With these data the air temperature at altitude was calculated using the ICAO standard atmosphere $[1,2]$. These temperatures were converted into equivalent chill temperatures according to SIPLE and PASSEL [2,3], and according to Danielsson [4] using the wind speed measured at Ulrichen. The day's average wind speed was used for "mean conditions", the day's maximum wind speed for „worst case conditions“. All calculations were performed with dry air temperature because humidity has a negligible effect at subfreezing temperatures.

A difference between both methods of less than $5^{\circ} \mathrm{C}$ in equivalent chill temperature was defined as ,identical'. In cases with a difference of more than $5^{\circ} \mathrm{C}$ the lower temperature was used for final evaluation. The temperature regression of each of Payerne's series was analyzed for linearity. In case of an inversion with an irregularity of temperature of more than $+/-5^{\circ} \mathrm{C}$ the method giving the lower temperature was used (in total at $9 / 456$ days, rsp. $2.0 \%$ of the whole period investigated). Seasonal differences were investigated by two subgroups. The first included missions in December, January, and February (,winter operations“, $\mathrm{n}=385$ ), the second those from July to September (,summer operations", $\mathrm{n}=329$ ).

The equivalent chill temperatures were classified according to the following systems: i. the German authorities for occupational safety (advices for medical checkup ,work in cold environment, G21") [5] $\left(>-25^{\circ} \mathrm{C}\right.$, $\left.-25--45^{\circ} \mathrm{C},<-45^{\circ} \mathrm{C}\right)$; ii. $5 \%, 50 \%$, and $95 \%$ risk level according to Danielsson [4], iii. the "classic" approach of Siple and Passel $\left(1,400\right.$ curve and $>-30^{\circ} \mathrm{C},-30--45^{\circ} \mathrm{C}$, $<-45^{\circ} \mathrm{C}$ ) [3], and iv. DIN 33403.5 ([6], see Table 1).

The insulation recommended was calculated according to ISO 11079 using the software of NILSSON and HOLMER (IREQ minimal and IREQ neutral) [7]. The same program was used to obtain DLE minimal and DLE neutral (Duration of Limited Exposure) and ICL according to ISO 9920 [8]. The calculations were based an a typical alpine clothing which has an insulation of about 2.0 clo (see table $\mathrm{C} 1$ in [9]), a metabolic energy production of $90 \mathrm{~W} / \mathrm{m}^{2}$ (mean value in ISO 8996 [10]), $0 \mathrm{~W} / \mathrm{m}^{2}$ of mechanical work, an air permeability of the clothing of $10 \mathrm{l} / \mathrm{m} 2 \mathrm{~s}$, and a relative air humidity of $85 \%$ [9]. Statistics were performed by non-parametric tests ( $\mathrm{x}^{2}$-test, Mann-Whitney-U-test). $P<0.05$ was defined as significant.

\section{Results}

$7 \%$ of the missions took place at low altitude (less than $1500 \mathrm{~m}$ ), $79.3 \%$ at moderate altitude (1500 - 3500 $\mathrm{m}$ ) and $13.7 \%$ at high altitude (3500 - $4560 \mathrm{~m}$, fig.1). Most operations were performed at wind speed of 3-6 Beaufort. For details about dry air temperature and wind speed see Fig.1. The temperature regression of the balloon ascents at Payerne showed a distinct linearity with a decrease of $-0.057^{\circ} \mathrm{C} / 100 \mathrm{~m}(+/-0.0098$, $\mathrm{n}=446$ ), which follows nearly ideal the regression of the ICAO standard atmosphere [1]. Only 9 days of 456 investigated $(2 \%)$ showed an inversion of more than $5^{\circ} \mathrm{C}$, mostly between 1400 and $2000 \mathrm{~m}$.

With the Siple-Passel-model and "worst case conditions" in $87.1 \%$ the chill temperature was above $-30^{\circ} \mathrm{C}$, in $12.1 \%$ between -30 and $-45^{\circ} \mathrm{C}$, and in $0.8 \%$ lower than $-45^{\circ} \mathrm{C}$. This is significant less than the situation at "mean conditions", where $99.5 \%$ of all 1082 operations took place at chill temperatures above $-30^{\circ} \mathrm{C}$ and $0.5 \%$ between -30 and $-45^{\circ} \mathrm{C}$. The lowest equivalent chill temperature in our investigation was $-54.6^{\circ} \mathrm{C}$, the highest $28.6^{\circ} \mathrm{C}$ (Fig.2). A wind chill effect of more than $-5^{\circ} \mathrm{C}$ was calculated for $34.8 \%$ of the missions. There were significant seasonal differences $(P<0.01$; Table 2, Fig.2). As expected most operations took place at

Table 1. Cold exposure and rewarming times according to DIN 33403.5

\begin{tabular}{|c|c|c|c|c|}
\hline Cold classification & $\begin{array}{c}\text { Air temperature } \\
{\left[{ }^{\circ} \mathrm{C}\right]}\end{array}$ & $\begin{array}{l}\text { Maximum time of } \\
\text { continuous cold } \\
\text { exposure } \\
\text { [min.] }\end{array}$ & $\begin{array}{l}\text { Recommended re- } \\
\text { warming time in \% of } \\
\text { cold exposure time } \\
{[\%]}\end{array}$ & $\begin{array}{c}\text { Recommended re- } \\
\text { warming time } \\
\text { [min. }]\end{array}$ \\
\hline 1 "cool" & +15 to +10 & 150 & 5 & 10 \\
\hline 2 "moderate cold" & $<+10$ to -5 & 150 & 5 & 10 \\
\hline 3 "cold" & $<-5$ to -18 & 90 & 20 & 15 \\
\hline 4 "very cold" & $<-18$ to -30 & 90 & 30 & 30 \\
\hline 5 "extreme cold" & $<-30$ & 60 & 100 & 60 \\
\hline
\end{tabular}



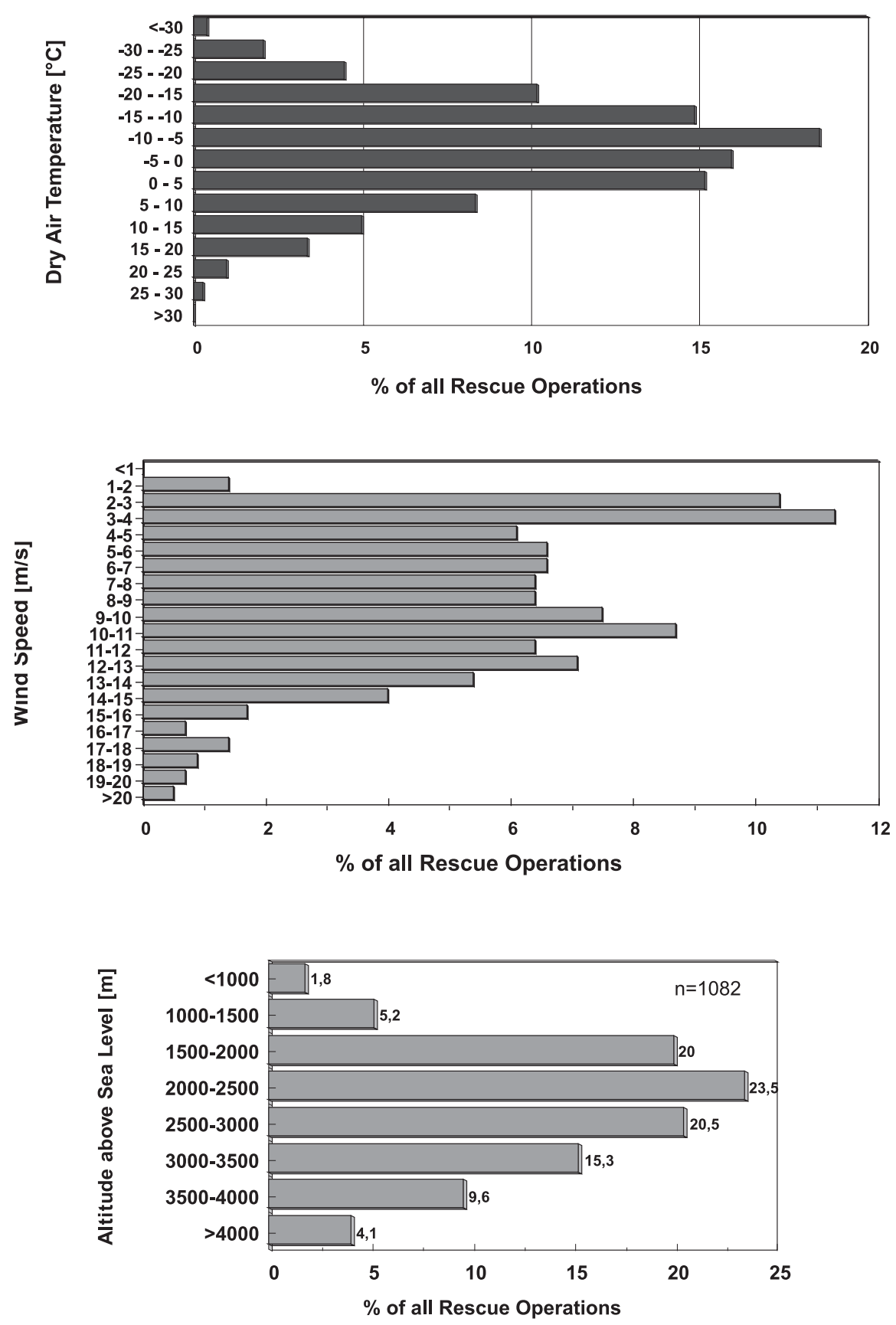

Fig.1. Dry air temperature, wind speed "on scene", and altitude of the rescue operations

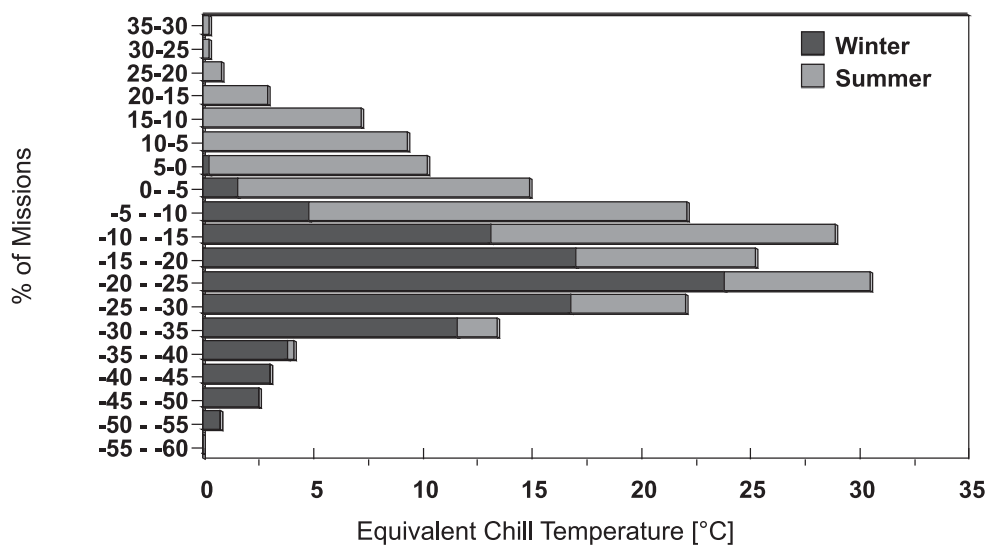

Fig. 2. Chill temperature on scene ("worst case"-calculation by model 1, see text) 


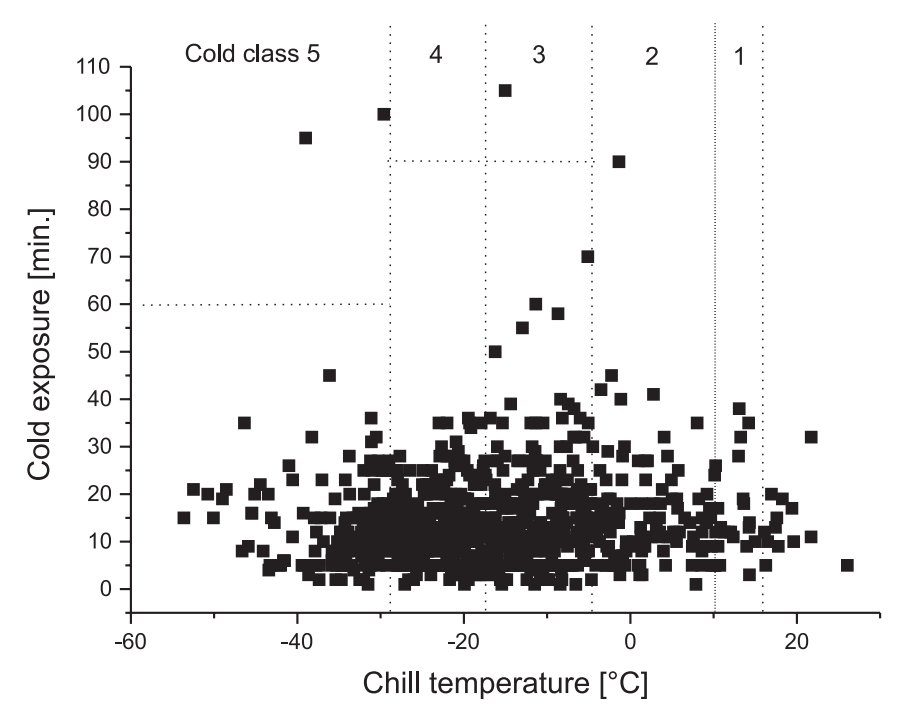

Fig. 3. Exposure conditions and cold classes according to DIN 33403.5 (worst case estimation, Siple-Passel-model, from [25])

Table 2. Seasonal differences of wind chill temperatures during rescue operations (Siple-Passel-model)

\begin{tabular}{|c|c|c|c|c|}
\hline \multirow{2}{*}{$\begin{array}{c}\text { Chill } \\
\text { Temperature } \\
{\left[{ }^{\circ} \mathrm{C}\right]}\end{array}$} & \multicolumn{2}{|c|}{$\begin{array}{l}\text { Summer operations } \\
\qquad(\mathrm{n}=306)\end{array}$} & \multicolumn{2}{|c|}{$\begin{array}{l}\text { Winter operations } \\
\qquad(\mathrm{n}=431)\end{array}$} \\
\hline & $\begin{array}{c}\text { "Average conditions" } \\
{[\%]}\end{array}$ & $\begin{array}{c}\text { "Worst case } \\
\text { conditions" } \\
{[\%]}\end{array}$ & $\begin{array}{c}\text { “Average conditions" } \\
{[\%]}\end{array}$ & $\begin{array}{c}\text { "Worst case } \\
\text { conditions" } \\
{[\%]}\end{array}$ \\
\hline$>-30$ & 100.0 & 96.0 & 99.7 & 81.2 \\
\hline-30 to -45 & 0.0 & 4.0 & 0.3 & 17.1 \\
\hline$<-45$ & 0.0 & 0.0 & 0.0 & 1.7 \\
\hline
\end{tabular}

Table 3. Seasonal differences in the risk of frostbite (Danielsson-model and Siple-Passel-model)

\begin{tabular}{ccccc}
\hline & \multicolumn{2}{c}{$\begin{array}{c}\text { Summer operations } \\
(\mathrm{n}=306)\end{array}$} & \multicolumn{2}{c}{$\begin{array}{c}\text { Winter operations } \\
(\mathrm{n}=431)\end{array}$} \\
\hline \multirow{2}{*}{ Risk of frostbite } & "Average conditions" & $\begin{array}{c}\text { "Worst case } \\
\text { conditions" } \\
{[\%]}\end{array}$ & $\begin{array}{c}\text { "Average conditions" } \\
{[\%]}\end{array}$ & $\begin{array}{c}\text { Worst case } \\
\text { conditions" } \\
{[\%]}\end{array}$ \\
\hline$<5 \%$ & 95.4 & 87.3 & 99.1 & 65.0 \\
$>5 \%$ & 4.6 & 8.2 & 0.9 & 34.8 \\
$>50 \%$ & 0.0 & 1.6 & 0.0 & 11.6 \\
$>95 \%$ & 0.0 & 0.3 & 0.0 & 4.2 \\
$<1400$ curve & 68.3 & 62.4 & 97.4 & 80.3 \\
$>1400$ curve & 31.7 & 37.6 & 2.6 & 19.7 \\
\hline
\end{tabular}

Table 4. Seasonal differences of whole body cold exposure according to DIN 33403.5

\begin{tabular}{|c|c|c|c|c|}
\hline \multirow[b]{2}{*}{ Cold class } & \multicolumn{2}{|c|}{$\begin{array}{l}\text { Summer operations } \\
\qquad(\mathrm{n}=306)\end{array}$} & \multicolumn{2}{|c|}{$\begin{array}{l}\text { Winter operations } \\
\qquad(\mathrm{n}=431)\end{array}$} \\
\hline & $\begin{array}{c}\text { "Average conditions" } \\
{[\%]}\end{array}$ & $\begin{array}{c}\text { "Worst case } \\
\text { conditions" } \\
{[\%]}\end{array}$ & $\begin{array}{c}\text { "Average conditions" } \\
{[\%]}\end{array}$ & $\begin{array}{c}\text { "Worst case } \\
\text { conditions" } \\
{[\%]}\end{array}$ \\
\hline$>1$ & 10.5 & 3.6 & 0.7 & 0.2 \\
\hline 1 & 11.1 & 4.9 & 1.2 & 0.5 \\
\hline 2 & 54.9 & 26.5 & 17.8 & 3.3 \\
\hline 3 & 20.3 & 39.2 & 53.9 & 28.1 \\
\hline 4 & 3.3 & 19.6 & 25.5 & 47.3 \\
\hline 5 & 0.0 & 6.2 & 0.9 & 20.6 \\
\hline
\end{tabular}


Table 5. Seasonal differences of wind chill temperatures during rescue operations (G21 classification)

\begin{tabular}{ccccc}
\hline Chill & \multicolumn{2}{c}{$\begin{array}{c}\text { Summer operations } \\
(\mathrm{n}=306)\end{array}$} & \multicolumn{2}{c}{$\begin{array}{c}\text { Winter operations } \\
(\mathrm{n}=431)\end{array}$} \\
\hline $\begin{array}{c}\text { Temperature } \\
{\left[{ }^{\circ} \mathrm{C}\right]}\end{array}$ & "Average conditions" & $\begin{array}{c}\text { "Worst case } \\
\text { conditions" } \\
{[\%]}\end{array}$ & $\begin{array}{c}\text { "Average conditions" } \\
{[\%]}\end{array}$ & $\begin{array}{c}\text { "Worst case } \\
\text { conditions" } \\
{[\%]}\end{array}$ \\
\hline$>-25$ & 100.0 & 95.4 & 93.0 & 65.0 \\
-25 to -45 & 0.0 & 4.6 & 7.0 & 33.3 \\
$<-45$ & 0.0 & 0.0 & 0.0 & 1.7 \\
\hline
\end{tabular}

Table 6. IREQ necessary for the operations, calculation according to ISO 11079

\begin{tabular}{|c|c|c|c|c|}
\hline \multirow[b]{2}{*}{ clo } & \multicolumn{2}{|c|}{ IREQ minimal } & \multicolumn{2}{|c|}{ IREQ neutral } \\
\hline & Sommer (\%) & Winter (\%) & Sommer (\%) & Winter (\%) \\
\hline \multicolumn{5}{|l|}{$<=0,5$} \\
\hline \multicolumn{5}{|l|}{$0,6-1,0$} \\
\hline $1,1-1,5$ & 5,6 & & & \\
\hline $1,6-2,0$ & 34,6 & 0,3 & 23,9 & \\
\hline $2,1-2,5$ & 29,7 & 7,4 & 26,5 & 1,9 \\
\hline $2,6-3,0$ & 13,4 & 17,2 & 22,9 & 9,0 \\
\hline $3,1-3,5$ & 12,1 & 28,6 & 16,3 & 22,5 \\
\hline $3,6-4,0$ & 2,0 & 26,5 & 6,9 & 27,8 \\
\hline $4,1-4,5$ & 2,3 & 14,0 & 2,0 & 23,8 \\
\hline $4,6-5,0$ & 0,3 & 5,6 & 1,6 & 11,6 \\
\hline $5,1-5,5$ & & 0,3 & & 3,2 \\
\hline $5,6-6,0$ & & 0,3 & & 0,3 \\
\hline$>6,0$ & & & & \\
\hline
\end{tabular}

Table 7. ICL necessary for the operations, calculation according to ISO 9920

\begin{tabular}{|c|c|c|c|c|}
\hline \multirow[b]{2}{*}{ clo } & \multicolumn{2}{|c|}{ ICL minimal } & \multicolumn{2}{|c|}{ ICL neutral } \\
\hline & Sommer (\%) & Winter (\%) & Sommer (\%) & Winter (\%) \\
\hline$<=0,5$ & & & & \\
\hline $0,6-1,0$ & & & & \\
\hline $1,1-1,5$ & & & & \\
\hline $1,6-2,0$ & & & & \\
\hline $2,1-2,5$ & 3,6 & & & \\
\hline $2,6-3,0$ & 14,4 & 1,9 & 2,3 & \\
\hline $3,1-3,5$ & 18,6 & 5,0 & 12,1 & 2,1 \\
\hline $3,6-4,0$ & 13,7 & 10,8 & 18,6 & 5,6 \\
\hline $4,1-4,5$ & 16,3 & 12,4 & 15,0 & 10,6 \\
\hline $4,6-5,0$ & 9,2 & 21,7 & 12,4 & 13,8 \\
\hline $5,1-5,5$ & 6,2 & 15,9 & 13,7 & 20,1 \\
\hline $5,6-6,0$ & 6,9 & 14,0 & 7,2 & 15,6 \\
\hline $6,1-6,5$ & 4,9 & 8,2 & 5,6 & 12,4 \\
\hline $6,6-7,0$ & 3,3 & 2,9 & 4,9 & 8,5 \\
\hline $7,1-7,5$ & 2,3 & 3,4 & 2,9 & 4,2 \\
\hline $7,6-8,0$ & 0,7 & 0,8 & 3,3 & 2,6 \\
\hline$>8,0$ & & 2,9 & 2,0 & 4,5 \\
\hline
\end{tabular}


temperatures being more comfortable at summer missions, but the data show a wide range at all seasons with very cold conditions also in summer (Fig.2).

With the Danielsson model and "mean conditions" there was no or minimal risk of frostbite in $97.2 \%$ of all rescue operations and in $2.8 \%$ a risk of $>5 \%$. At "worst case conditions" the corresponding results are $77.6 \%$ with no risk, $20.1 \%$ with $>5 \%$ risk, $6.0 \%$ with $>50 \%$ risk, and $1.8 \%$ with $>95 \%$ risk. For comparison $85 \%$ of the operations show no risk according to the 1400-curve of Siple-Passel and 15.0\% an increased risk ("mean conditions"). Assuming "worst case conditions" the corresponding data are $72.9 \%$ rsp. $27.1 \%$. As expected there are significant differences between summer conditions and winter operations with the Danielsson-model as well $(P<0.01$; Table 3$)$.

The classification according to DIN 33403.5 shows $4.7 \%$ of all rescue operations with temperatures above cold class $1,5.0 \%$ class $1,39.6 \%$ class $2,38.5 \%$ class 3 , $11.6 \%$ class 4 , and $0.5 \%$ class 5 ("mean conditions"). With "worst case conditions" the corresponding values are $1.5 \%, 2.3 \%, 13.3 \%, 34.7 \%, 34.6 \%$, and $13.7 \%$. Again there are significant differences between summer and winter operations $(P<0.01$; table 4$)$. Classified according to G25 $97.3 \%$ of all operations took place at temperatures $>-25^{\circ} \mathrm{C}$, and additional $2.7 \%$ between $-25^{\circ} \mathrm{C}$ and $-45^{\circ} \mathrm{C}$ ("mean conditions"). Assuming "worst case conditions" the corresponding values are $78.2 \%, 21.0 \%$, and $0.8 \%$ at $<-45^{\circ} \mathrm{C}$. Again there are significant differences between summer and winter operations $(P<0.01$; Table 5$)$.

The mean time of exposure was 15.3 (+/-30.2) minutes but with remarkable variation up to 850 minutes. This mission was performed at a chill temperature of $-22^{\circ} \mathrm{C}$ at an altitude of $3500 \mathrm{~m}$ (Siple-Passel-model, "worst case" calculation). There was no significant difference in the duration between summer and winter operations. According to DIN 33403.5 the recommended maximal exposure times were certainly exceeded in $0.5 \%$ of all missions ( $2 \mathrm{x}$ in cold class 3 , $2 \mathrm{x}$ in class 4 , and $1 \mathrm{x}$ in class 5 , Fig. 3 ). Additionally there may be some more in cases when the following mission starts shortly after the previous was finished.

The insulation recommended by ISO 11079 and ISO 9920 is sufficient in $40.2 \%$ (IREQ min.) rsp. $23.9 \%$ (IREQ neutr.) at summer operations, but it is sufficient in only $0.3 \%$ (IREQ min.) in winter operations $(0.0 \%$ for IREQ neutr., tables $6 \& 7$ ). In summer operations the duration of limited exposure (DLE) is exceeded in 9.1\% (DLE min.) and in 19.8\% (DLE neutr.) respectively (Tables $6 \& 7$ ). The mean duration of the summer operations is $61.9 \%(+/-277.8)$ of DLE min. rsp. $75.8 \%$ (+/-279.2) of DLE neutr. The maximal exceed of DLE was $4722 \%$ when the whole team was blocked during a rescue operation at the Matterhorn by bad weather with an ambient air temperature of $-3.7^{\circ} \mathrm{C}$ and a wind speed of $11.3 \mathrm{~m} / \mathrm{s}$. In Winter DLE min. is exceeded in $10.3 \%$ of the operations, DLE neutr. in $19.1 \%$. The mean duration is $57.9 \%(+/-42.2)$ rsp. $67.3 \%(+/-51.5)$ of DLE min. rsp. DLE neutr. The maximum exceed of DLE was 417\% (DLE min.) rsp. 556\% (DLE neutr.) during a rescue operation at ambient conditions of $-1.1^{\circ} \mathrm{C}$ air temperature and $6.4 \mathrm{~m} / \mathrm{s}$ wind speed. The difference of DLE exceed in summer and winter was not significant (neither DLE min. nor DLE neutr.). According to ISO 9920 a clothing with 2.0 clo is not sufficient in all summer and winter operations.

\section{Discussion}

In our study the cold exposure of the personnel during alpine rescue operations was quantified by two independent approaches and the results were classified according to several well established systems. The data show that the exposure regularly exceeds the DLE and the risk of frostbite and potentially also for hypothermia is common. During alpine rescue operations, the personnel is exposed to a wide variety of environmental factors like hypobaric hypoxia, low temperatures, wind, and radiation as well as extreme helicopter noise, and high work load. In contrast to most other professions these factors change over a wide range depending on the location of the mission, the weather conditions, and the situation on scene. Additionally they often change very abrupt during the mission and current technology for measuring meteorological data direct at the site of an alpine accident during the rescue operation does not yet permit accurate data of cold exposure and extensive measuring during rescue operations is impracticable and ethically questionable. However, it was nonetheless possible to get an appraisal of the cold exposure of the personnel under these circumstances because there were only minimal differences (only $2 \%$ of the days investigated) between two independent methods for estimation which means that the risk appraisal was nearly independent from the method used.

Holmer discusses five principal cooling mechanisms: i. whole-body cooling, ii. extremity cooling, iii. convective cooling (wind chill), iv. conductive cooling (contact), and v. airway cooling [11]. With whole-body and extremity cooling being less important in a situation of alpine rescue (mainly because of the limited exposure time during most operations), conductive cooling being easily prevented by using adequate clothing (although conductive cooling is not avoidable in every situation), and airway cooling actually being impossible to use because it depends mainly on the breathing volume respectively the work load which is unknown for alpine rescue operations, we used the model of convective cooling for our estimations. Because normally there is wind at the place of an alpine accident, the wind chill models should work best. 
Since this model was first introduced by Siple and Passel in 1945 it was in discussion, mainly because it works exactly only if the skin exposed is unprotected [3,12-15]. Some authors argue also that the human's thermal response depends not only on physical conditions and physiological state, e.g. metabolic rate, but also on past experience, how people perceive the environment, and how weather conditions differ from the norm [14]. Most authors criticise it mainly because the underlying model does not comply with modern heat transfer theory (survey in [16]). Therefore other indicators like exposed skin temperature and maximum exposure time or for conductive cooling contact coefficient and maximum exposure time were suggested [16,17]. Although the original model was limited to wind speed of $12 \mathrm{~m} / \mathrm{s}$ it is well accepted to extrapolate the model above this limit [e.g. 4,18]. The minimal error of the original model which underestimates the effect of wind speed and which was caused because the surface temperature of the cylinder used was not - as it was expected - similar to that of the freezing water is also accepted [4]. The consequence is that the Siple-Passel-Model indicates a greater risk than the $5 \%$-curve of Danielsson, but at less than $-20^{\circ} \mathrm{C}$ it gives a minor risk [4]. However, as Danielsson points out, at these low temperatures a change of the airspeed of $2-3 \mathrm{~m} / \mathrm{s}$ can change the risk by $>50 \%$ [4]. All the risk curves therefore should be used with caution, because minor changes in the climatic, behavioral, or physiological conditions can have a considerable effect on the risk of tissue freezing [4]. In consequence the differences between the models of Siple/Passel and Danielsson are of minor consequence for the question investigated in our study.

The more widely used wind chill equivalent temperature represents another attempt to combine environmental factors into a single index to indicate human comfort and it describes the amount of cold exposure and the risk for cold weather injuries quite well [19-23]. Such an agreement of equivalent wind chill temperature and heat loss exists also for the full range of civilian outdoor clothing although wholebody heat-loss through clothing was lower than predicted by Siple's model [19-21].

In our study both approaches showed comparable results. Major differences between the two approaches in our study, which means $+/-5^{\circ} \mathrm{C}$ or more, are limited to only $2 \%$ of the whole period which means that they are of minimal influence on the general estimation of cold exposure. So the equivalent chill indices calculated for each mission included should be relatively correct, although some factors like local winds or lee situations could not be considered.

The risk for cold weather injuries with strong winds and low temperatures is undisputed (e.g. $[11,22,23])$. $99.3 \%$ of all cold weather injuries of U.S. soldiers $(\mathrm{n}=$ 273) are first- and second degree frostbite and $71 \%$ of them happened at equivalent wind chill temperatures of $<-29^{\circ} \mathrm{C}$ [22]. Interestingly the risk of cold weather injuries increases at significantly milder weather conditions than previously published cold hazard charts suggest [23]. In this study the risk increased significantly at $-12^{\circ} \mathrm{C}$ resting air temperature and wind velocity $>4.5 \mathrm{~m} / \mathrm{s}$ (Beaufort 3 ). These conditions are within the range of most operations investigated in our study. Therefore and because cold stress reduces work ability in 70\% [21], alpine rescue personnel should be given special advices to prevent cold weather injuries.

Because our "mean conditions" underestimate the real conditions of many operations worst case conditions should be used for risk evaluation. In DIN 33403.5 work in cold environment is defined as "work with air temperatures below $+15^{\circ} \mathrm{C}$ and where humans show a negative heat balance in spite of the effects of workload and clothing". With $34.7 \%$ of the operations in cold (class 3 ) and $48.3 \%$ in very cold and extreme cold environment (class $4 \& 5$ ) our data show a surprising extreme exposure of the personnel. Although the recommended maximum of exposure time was exceeded only in $0.5 \%$ of the missions, it must be pointed out that these recommended limits of exposure time base on adequate clothing.

The typical "alpine" clothing has an insulation effect of about 2.0 clo [10]. Our calculations according to [9] showed that the clothing is not sufficient for a considerable amount of operations. The difference between the results according to ISO 11079 and ISO 9920 are mainly caused by the fact that the influence of wind chill is more important in the calculations according to ISO 9920. But in most cases the excess of duration of exposure (DLE) is limited and therefore hypothermia should be mild in most cases. This is corresponding to the feeling of the rescuers who often report shivering but rarely symptoms of moderate or severe hypothermia. But nevertheless it must be pointed out that in $1.4 \%$ respectively $2.7 \%$ (DLE min. or neutr.) of the summer and $0.8 \%$ respectively $1.4 \%$ of the winter operations DLE is exceeded for more than $200 \%$. In these cases danger by hypothermia must be assumed for the rescuers and of course even more for the patient. In consequence the content of the rescuer's backpack should be reconsidered, because normally there isn't any additional clothing or a bivouac sack included in the equipment of air rescue members. Especially for questionable or bad weather conditions additional clothing should be a "must".

The main problem of adequate clothing for alpine helicopter rescue are the quickly changing conditions with +15 to $+20^{\circ} \mathrm{C}$ (and more) in the helicopter's cabin and $-20^{\circ} \mathrm{C}$ (and less) only minutes later at the site of the accident. Because most helicopters used for alpine rescue being too small to be reentered in-flight at the end of any winch operation, the personnel as well as the patient stay outside until an intermediate landing 
will be reached and therefore exposed to extreme wind chill during the flight. In our study this period had a mean duration of 6.3 minutes $(+/-2.53, \mathrm{n}=163)$. During this period the personnel is exposed to wind speed up to $160 \mathrm{~km} / \mathrm{h}$ (and sometimes even more) resulting in extreme equivalent wind chill temperatures and an extreme risk of frostbite. In contrast to the personnel, the risk for the patient is minimal, because normally he will be carried in the rescue bag.

Our data indicate the need of preventive advices and care for the crews by occupational medicine, e.g. according to the medical check-up „working in cold environment (G21)“ in Germany [5]. Special regard should be given to persons with medical problems which cause increased risk for cold injuries. In most cases these people need to be excluded from alpine rescue operations. The best prevention of cold weather injuries regarding the quickly changing conditions during the mission is clothing with several insulating inner layers and a good wind protection as outer layer. During winch operations a simple trick reduces effectively the risk of frostbites in the face: As soon as the rescuer is winched up and reaches the helicopter's skid with his hands, he can turn around to expose his back towards the wind with the hood protecting neck and head. Along with it should be pointed out, that the victim is exposed to the conditions discussed above as well, and in most cases even longer than the rescue team: Although more than $50 \%$ of the emergency calls a cellular phone is used in the region [24] and the helicopter base is directly in Zermatt nearby, it needs 27,9 $+/-59,4$ minutes $(\mathrm{n}=1082)$ for most of the mountains climbed until the rescue crew arrives. Because of this significant longer exposure than the rescuers $(P<0.001)$ the patient's risk for hypothermia is higher than those of the rescuers. Therefore every mountaineer or skier must be well educated in cold protection.

\section{Acknowledgements}

The authors would like to express their gratitude to Swiss Meterological Institution and Air Zermatt AG, Zermatt / Switzerland for their support.

\section{Declaration of interest}

The authors report no conflicts of interest.

\section{References}

1. N.N. Manual of the ICAO Standard Atmosphere. 2nd ed. ed, ed. ICAO. Montreal: ICAO, 1964.

2. Ernsting J, King P. Aviation Medicine. 2nd ed. ed. Oxford: Butterworth-Heinemann Ltd, 1994.

3. Siple P, Passel C. Measurements of dry atmospheric cooling in subfreezing temperatures. Proc Am Philosoph Soc 1945; 89: 177-99.
4. Danielsson U. Windchill and the risk of tissue freezing. J Appl Physiol 1996; 81(6): 2666-73.

5. N.N. Berufsgenossenschaftliche Grundsätze für arbeitsmedizinische Vorsorgeuntersuchungen, G21 "Kältearbeiten". Stuttgart: Gentner Verlag, 1998.

6. N.N. DIN 33403.5: Klima am Arbeitsplatz: Kältearbeitsplätze. 1996.

7. Nilsson HO, Holmer I. Calculation of the required clothing insulation (IREQ), duration limited exposure (DLE), required recovery time (RT) (IREQ 2002 Ver 3.1a). Stockholm, 2002.

8. N.N. ISO 9920: Ergonomics of the thermal environment - Estimation of the thermal insulation and evaporite resistance of a clothing ensemble. International Organization for Standadrization: Genf / Schweiz, 1995.

9. N.N. ISO 11079: Bestimmung der erforderlichen Isolation der Bekleidung (IREQ). Deutsches Institute für Normung: Berlin, 1993.

10. N.N. ISO 8996: Bestimmung der Wärmeerzeugung im menschlichen Körper. Deutsches Institut für Normung e.V.: Berlin, 1993.

11. Holmer I. Work in the cold. Review of methods for assessment of cold exposure. Int Arch Occup Environ Health 1993; 65(3): 147-55.

12. Siple P, Passel C. Excerpts from: Measurements of dry atmospheric cooling in subfreezing temperatures. Wild Environm Med 1999; 10: 176-82.

13. Kaufman WC, Bothe DJ. Wind chill reconsidered, Simple revisited. Aviat Space Environ Med 1986; 57(1): 23-6.

14. Kaufman WC, Laatsch WG, Rhyner CR. A different approach to wind chill. Aviat Space Environ Med 1987; 58(12): 1188-91.

15. Paton B. Paul Siple and the origin of windchill - a commentary. J Wild Environm Med 1999; 10: 174-5.

16. Brauner N, Shacham M. Meaningful wind chill indicators derived from heat transfer principles. Int J Biometeorol 1995; 39(1): 46-52.

17. Havenith G, Heus R, Daanen HA. The hand in the cold, performance and risk. Arctic Med Res 1995; 54(Suppl 2): 37-47.

18. N.N. DIN ISO 11079 Bestimmung der erforderlichen Isolation der Bekleidung (IREQ). Berlin: Beuth Verlag, 1998.

19. Wyon DP. Wind-chill equations predicting whole-body heat loss for a range of typical civilian outdoor clothing ensembles. Scand J Work Environ Health 1989; 15(Suppl 1): 76-83.

20. Virokannas H, Anttonen H. Thermal responses in the body during snowmobile driving. Arctic Med Res 1994; 53(Suppl 3): 12-8.

21. Anttonen H, Virokannas H. Assessment of cold stress in outdoor work. Arctic Med Res 1994; 53(1): 40-8.

22. Candler WH, Ivey H. Cold weather injuries among U.S. soldiers in Alaska: a five-year review. Mil Med 1997; 162(12): 788-91.

23. Sinks T, Mathias CG, Halperin W, et al. Surveillance of workrelated cold injuries using workers' compensation claims. $J$ Occup Med 1987; 29(6): 504-9.

24. Jelk B. Unfälle des Jahres 1999. Clubnachrichten des SAC Zermatt 2000; 25(1): 6.

25. Kupper T, Steffgen J, Jansing P. Cold exposure during helicopter rescue operations in the Western Alps. Ann Occup Hyg 2003; 47(1): 7-16.

Received: January 04, 2012

Accepted: June 04, 2012

Published: June 29, 2012

Address for correspondence:

Thomas Küpper, Prof., PhD, MD

Institute of Occupational and Social Medicine

RWTH Aachen University

Pauwelstr. 30

52074 Aachen, Germany

e-mail: tkuepper@ukaachen.de

Jürgen Steffgen: jsteffgen@gmx.de

Paul Jansing: jansing@uni-duesseldorf.de

Volker Schoeffl: Volker.Schoeffl@t-online.de

\begin{tabular}{llll}
\hline Authors' contribution & B - Data Collection & D - Data Interpretation & F- Literature Search \\
A - Study Design & C - Statistical Analysis & E - Manuscript Preparation & G - Funds Collection
\end{tabular}

